\title{
Crise, uma condição intrínseca à modernidade: realidades e horizontes da sociedade contemporânea
}

BAUMAN, Zygmunt; BORDONI, Carlo. Estado de crise. Rio de Janeiro: Zahar, 2016.

Rodolfo Rodrigo Santos Feitosa*

$\square$

stado de crise é uma daquelas obras que aguçam nossa capacidade reflexiva quanto aos fenômenos sociais, políticos e econômicos contemporâneos. Não seria demais afirmar que o olhar crítico sobre o presente e o ceticismo em relação ao futuro próximo acabam por deixar no leitor certa apreensão quanto aos próximos eventos da história global. Embora não se configure como um tratado teórico minucioso, o diálogo existente nesse livro, entre o consagrado sociólogo da "liquidez", Zygmunt Bauman, e o escritor, jornalista e também sociólogo Carlo Bordoni é bastante profícuo e valioso aos leitores de áreas acadêmicas afins à sociologia, com grande potencial para agradar também àqueles menos íntimos deste campo científico.

Do ponto de vista estilístico, a obra é uma alternância entre a pujante escrita característica da pena de Bauman, a qual chega a assumir, por vezes, certo tom poético, e a arquitetada pronúncia objetiva de Bordoni. O diálogo alternado, utilizado como forma de exposição do livro, seria provavelmente notado por um leitor assíduo de Bauman, ainda que fossem suprimidas as identificações prévias acerca do expositor da vez, pois as distintas escritas são reveladoras dos momentos de fala de cada um. Acreditamos, neste sentido, que a distinção de fontes tipográficas utilizada pela editora a fim de destacar a fala de cada um dos autores no corpo do texto, embora fundada em propósito plausível, acaba por gerar certo incômodo estético, mas nada que atrapalhe a boa leitura que a obra proporciona. Restaria suficiente, neste caso, o artifício já utilizado de destaque do nome de cada autor antes do início de sua passagem como forma de identificá-lo ao longo do texto. Ademais, o padrão gráfico de excelência permanece intacto e homogêneo aos demais títulos de Bauman publicados por essa editora.

Marcada por um senso crítico mordaz e elucidador acerca da realidade social, econômica e política contemporânea, este livro é uma contribuição significativa para a
Recebido: 26.07.16 Aprovado: 19.12 .16

\author{
* Bacharel e mestre \\ em ciências sociais \\ pela Universidade \\ Federal de Campina \\ Grande (UFCG). \\ Doutor em sociologia \\ pela Universidade \\ Federal de \\ Pernambuco (UFPE). \\ Professor do Instituto \\ Federal do Sertão \\ Pernambucano. \\ Pesquisador com \\ estudos nas áreas \\ de teoria social \\ contemporânea, \\ sociologia da \\ globalização e \\ sociologia rural. \\ <rrfeitosa@gmail. \\ com>.
}


apreensão dos cenários de crise que afetam o mundo nos dias de hoje. Sem desprezar as evidências históricas relevantes ao entendimento das conjunturas atuais de notória instabilidade e insegurança, sobretudo política e econômica, Bauman e Bordoni caminham no sentido de esclarecer alguns dos porquês tanto no que se refere ao estado de crise permanente quanto à crise do Estado. Em outros termos, os autores abordam tanto essa circunstância permanente em que vivemos, onde as crises são indissolúveis integralmente e, por assim dizer, existem como elemento inexpugnável à realidade hodierna. Do mesmo modo, dão vazão a reflexões sobre a perda de poder do Estado moderno cuja capacidade resolutiva diante de situações críticas foi minada pela sobrevalorização da esfera econômica e das instâncias supraestatais a ela atreladas.

A obra em questão é dividida em três grandes partes, no âmbito das quais se estruturam os capítulos específicos, sendo cada um deles, neste sentido, uma composição mesclada das ideias de Bauman e Bordoni. A impressão causada pelo arranjo de cada capítulo é de que os autores não pretenderam compor um raciocínio de percurso retilíneo e homogêneo, antes intencionaram construir conjuntamente a argumentação de cada debate, a partir da soma de argumentos e sem diluir as peculiaridades de entendimento que cada um deles guarda. Deste modo, a discussão da primeira seção do livro diz respeito à problemática circunstância da indissolução das crises que afetam o Estado moderno, bem como os fundamentos que trouxeram tão malograda condição a esse pilar institucional da modernidade. A segunda parte, por sua vez, trata da crise da modernidade evidenciada pelo não cumprimento de suas promessas, sobre a qual passa a pairar a sombra desuniforme da pós-modernidade. Na última seção, estão contidos os capítulos que debatem, dessa vez, a crise do modelo democrático em vigência, o qual tem se mostrado ineficiente na realização de seus propósitos, oscilantes e, não raro, incongruentes com os meios utilizados.

A reflexão que predomina na primeira parte da obra aponta não apenas para a condição permanente das incontáveis crises na história político-econômica recente, mas, principalmente, para o fato destas representarem, em outro patamar, a falência do Estado-nação como agente soberano. Os dois autores consolidam argumentos destacando esse atributo turbulento da realidade contemporânea, que diz respeito à onda sucessiva de crises que afetam os países; à escassez de ferramentas concretas de solução decisiva destas anormalidades que deveriam ser passageiras. Essa notória insuficiência resolutiva das situações de crise corresponde à condição atual do Estado moderno, cuja falência do poder de agência e redução da potência de ação efetiva estão atreladas à sobrevalorização da esfera econômica, ao domínio do capital móvel e ao fortalecimento dos espaços e instâncias decisórias supraestatais. 
Neste sentido, a crise do Estado a que se refere Bauman e Bordoni (p. 22, grifo dos autores) decorre do "divórcio entre poder e política" promovido pela apartação da esfera econômica dos marcos regulatórios e limitadores. O mercado, o capital e seus fluxos prescindem das antigas amarras territoriais e normativas do Estado já há algum tempo, mas encontram agora nas formas supraestatais globalizadas as instâncias de exercício de suas autorregulações. Dessa forma, portanto, o Estado, despojado de seu poder efetivo de resolução, carece da capacidade de agência que o tornava respeitável e matinha os cidadãos crédulos à solução das demandas possíveis em tempos de apuros. A ideia de "estatismo sem Estado" (tomada por empréstimo do filósofo francês Étienne Balibar) - levantada ainda na parte primeira do livro - indica íntima conexão com a crise de agência, na medida em que esta sinaliza a incapacidade do Estado em lidar com os "problemas globais" que se fazem concretos sobre seu território, pois o poder para tal mora agora em níveis supraestatais econômicos.

O decorrente declínio da confiança popular na capacidade resolutiva do Estado reflete também o enfraquecimento da "nação" enquanto sentimento comunitário. Inviáveis financeiramente e reprováveis no modelo neoliberal, a atenção do Estado para com os indivíduos sob sua tutela é reduzida a quase nada, e em meio às conturbações estes são abandonados à própria sorte. Fica fácil deduzir que esse Estado atual em muito se distancia da figura imponente do Leviatã, uma vez que opera sob outras racionalidades e princípios estimuladores do individualismo e coadunados com modelo neoliberal de gestão administrativa.

Ao tratarem da crise da modernidade na segunda parte da obra, os autores guardam certas divergências de entendimento que serão manifestas ao longo desse trecho em diferentes passagens. É neste sentido que o livro nos apresenta, indubitavelmente, um belo diálogo intelectual que transita em torno de questões conexas, mas com ênfases diferenciadas sobre um ou outro aspecto e que nem sempre mantêm compreensões afins. Esse diálogo marcado pela contenção de Bauman sobre as assertivas altivas de seu interlocutor é mais evidente no decurso desse segmento segundo, quando os autores debatem os processos de ruptura na modernidade - sua crise, por assim dizer -, a emergência e a possível decomposição da pós-modernidade.

Por vezes, a exposição de um vai confrontar algo anteriormente apresentado pelo outro nesse trecho, tal como ocorre quando discutem o fato de a modernidade abandonar as suas "promessas" com o decorrer do movimento histórico. Nesta passagem em particular é notória a relutância de Bauman não apenas em aceitar que as promessas da modernidade foram abandonadas, motivo pelo qual não acredita 
ser apropriado o uso que seu colega faz do termo promessas para denominar aquilo que ele julgou ser "estratégias" e "ilusões" de uma fase juvenil da modernidade. Há também certa ressalva de Bauman em incorporar um tom de prognóstico à sua fala, tal como o faz Bordoni ao suscitar o fim da modernidade. A parcimônia em afirmações decisivas emerge suavemente na fala do polonês, refletindo os anos de pesquisa, os debates ao longo da carreira acadêmica e a experiência com eles acumulada.

Os trechos nos quais Bordoni faz valer sua pena são marcados pela inclinação deste autor à apresentação do movimento histórico com ênfase na superação sucessiva de fases, uma espécie de alteração permanente de cenas. À primeira vista, o ritmo possante que ele utiliza em sua exposição soa um tanto vertiginoso, até mesmo para os fiéis da aniquilação do "tempo moderno". Essa impressão pode ser diluída em uma segunda leitura, quando mais facilmente se nota que esta postura argumentativa, deveras convicta, é inerente ao seu modo de entendimento e ao estilo de escrita que Ihe é peculiar. Essa cadência parece não agradar Bauman que, em tom respeitoso, porém não completamente isento de ironia, tenta refrear algumas dessas investidas argumentativas de Bordoni notoriamente excessivas quanto à convicção, sobretudo quando apressadamente decretam desfechos para a sociedade.

Por ocasião da reflexão levada a cabo nessa segunda parte da obra, Bauman retoma as ressalvas que mantém quanto à ideia de pós-modernidade e que o induziram a cunhar o termo "liquidez" com o intuito de se referir à elevada frequência e volatilidade das mudanças ocorridas na sociedade moderna em sua fase avançada.

A liquidez representaria, por assim dizer, esse estágio em que a modernidade vivencia um processo de crise radical (Bauman, 2001: 9). Esse momento crítico, contudo, gerou uma enxurrada de prefixos "pós" que tentaram nominar o interregno ainda não concluso entre a modernidade e esse outro momento distinto. Aqui, portanto, o entendimento defendido por ambos é de que "a pós-modernidade se caracterizou pela crise das bases que sustentavam a modernidade, ideologia, história e ética do trabalho", mas não como esse momento novo distinto (p. 132). O limbo deixado pela pós-modernidade é este estado de crise permanente em que o tempo de referência é um eterno presente, sem apego às memórias, isto é, ao passado construído, e a partir do qual se vislumbra o futuro por frestas pouco iluminadas.

O terceiro momento do livro põe o leitor diante da crise do modelo democrático. Para tanto, os autores ventilam a ideia de que o individualismo, o consumismo, a desmaterialização do trabalho e a sensação de liberdade suprema difundidos pelo paradigma neoliberal e assumidos como propósitos parciais a serem perseguidos 
pela sociedade, acabam por se configurar como malogros que trazem em seu revés ainda mais incertezas e inseguranças aos indivíduos. Entretanto, a crise da democracia não é algo à parte, por assim dizer, e sim mais uma reverberação do descompasso que abate a modernidade em seu estágio de liquidez extrema. Nesta perspectiva, alguns elementos anteriormente expostos são aqui retomados, como, por exemplo, a tendência ao crescimento da "antipolítica" que representa em uma de suas faces a aversão dos indivíduos à esfera política decorrente do fracasso do Estado no provimento adequado dos serviços públicos.

Ainda neste segmento do livro, os autores refletem sem reservas o sentido oscilante que a democracia manifesta ao longo da modernidade, com diferentes variações nos contextos históricos diversos. Desta forma, a democracia representativa, em sua forma derradeira colapsada, é passível de ser compreendida pela evidência da cisão entre cidadãos e política. Em torno desta cisão quase irreparável, os autores acionam duas chaves possíveis de entendimento para apreensão dessa crise da democracia, a saber, a ideia de "desdemocratização" - originariamente apresentada por Charles Tilly - e a concepção de "pós-democracia" - tomada por empréstimo de Colin Crouch. Ao passo que a primeira sinaliza para a emergência de governos antidemocráticos em circunstâncias peculiares, entrelaçadas com medidas que esvaziam o compromisso social do Estado, como aponta Isabel Cunha (2015: 40); a segunda enfoca a condição antipolítica, na qual os indivíduos se distanciam da política e perdem progressivamente a confiança no Estado. Assim, solapada pelo estado de incerteza trazido com a pós-modernidade (considerada fase crítica da modernidade), a sociedade contemporânea carece de um Estado que revele poder efetivo de intervir nos cenários de crise e mantém-se, por conseguinte, em um modelo democrático cuja falência parece decretada na apartação entre cidadãos e esfera política.

Poderíamos dizer, por fim, que o arguto senso de realidade contido nas sentenças afiadas dos autores quanto à turbidez do cenário global contemporâneo, em especial no que pesa o desfalecimento do Estado e seu modelo democrático, pode causar uma sensação não muito agradável de pessimismo e melancolia. Conquanto essas lúcidas sentenças possam ser classificadas como demasiadamente incrédulas pelos críticos mais esperançosos, ainda assim, são o que de melhor oferece o exercício analítico da obra. Com efeito, um leitor que pretenda utilizar a referida obra como ferramenta para tornar inteligível a realidade contemporânea certamente não se arrependerá, pois embora não encontre na mesma um empreendimento teórico holístico, mesmo assim terá ao seu dispor um refinado apanhado de reflexões sobre aspectos e elementos relevantes da conjuntura crítica pela qual passa o Estado moderno e sua forma particular de democracia representativa. 


\section{Referências}

BAUMAN, Zygmunt. Modernidade líquida. Rio de Janeiro: Zahar 2001.

CUNHA, Isabel Ferin. Da "desdemocratização" da Europa: democracia, media e corrupção política. Intercom - RBCC. v. 38, n. 1, p. 37-63, 2015. Disponível em: <www. scielo.br/pdf/interc/v38n1/1809-5844-interc-38-01-0037.pdf>. Acesso em: 30 Jun. 2016. 